\title{
Experiência De Um Serviço De Medicina Fetal De Referência Do Sul Do Brasil Com Fetos Diagnosticados Com Trissomia Do Cromossomo 18 (Síndrome De Edwards)
}

\author{
Foscarini, A.C.; Sartori, G.D.P.; Gonzáles, J.F.O.; Krieger, E.R.; Denardin, D.; \\ Rosa, R.F.M.; \\ Apresentador: Ana Carolina Foscarini
}

\section{Resumo}

Introdução: a trissomia do cromossomo 18, ou síndrome de Edwards (SE), é uma doença cromossômica considerada grave. Ela se caracteriza pela presença de malformações usualmente envolvendo múltiplos órgãos. Nosso objetivo foi relatar a experiência de um serviço de medicina fetal com fetos diagnosticados com SE. Método: A amostra foi composta por uma série de pacientes diagnosticados com SE no Serviço de Medicina Fetal do Hospital Materno Infantil Presidente Vargas no período de 2008 a 2013. Foram coletados dados clínicos, radiológicos e prognósticos a partir dos seus prontuários. Resultados: neste período de 6 anos foram diagnosticados 9 pacientes com SE. Todos foram encaminhados pela presença de malformações. A média da idade gestacional na primeira avaliação foi de 24,3 semanas. Idade materna avançada (?35 anos) foi verificada em seis casos (67\%). Quatro pacientes (44\%) foram submetidas ao rastreamento ultrassonográfico de primeiro trimestre. Três deles (75\%) foram alterados. Oito pacientes foram submetidos à ultrassonografia obstétrica $(89 \%)$, sete $(78 \%)$ à morfológica e cinco à ecocardiografia (56\%). Todos os fetos apresentavam malformações múltiplas. As principais alterações observadas consistiram de cardiopatia congênita $(n=6)$, micrognatia $(n=$
2), artéria umbilical única $(\mathrm{n}=2)$ e onfalocele $(\mathrm{n}=$ 2). Morte intrauterina ocorreu em quatro pacientes (44\%). De todos os pacientes, 6 (67\%) eram do sexo feminino. Todos os pacientes vivos $(\mathrm{n}=5)$ nasceram através de parto cesáreo. Baixo peso ao nascer ( $<2.500$ gramas) e escores de Apgar ? 7 no primeiro e quinto minutos foram observados em todos os casos. A sobrevida variou de 1 a 378 dias (mediana de 18 dias). Conclusões: A identificação pré-natal de fetos com SE é de grande importância para a família e a equipe médica, pois fornece informações importantes sobre o manejo e o prognóstico. A sobrevida prolongada é considerada pouco frequente.

\section{Referência:}

Foscarini, A.C.; Sartori, G.D.P.; Gonzáles, J.F.O.; Krieger, E.R.; Denardin, D.; Rosa, R.F.M.;. Experiência De Um Serviço De Medicina Fetal De Referência Do Sul Do Brasil Com Fetos Diagnosticados Com Trissomia Do Cromossomo 18 (Síndrome De Edwards). In: II Congresso Brasileiro de Medicina Hospitalar - II CBMH [= Blucher Medical Proceedings, vol.1, num.5] São Paulo: Editora Blucher, 2014. p.60

DOI 10.5151/medpro-II-cbmh-057 